\title{
Herpes simplex meningitis after vestibular schwannoma surgery: illustrative case
}

\author{
Leonidas Trakolis, MD, ${ }^{1}$ Georgios Naros, MD, ${ }^{1}$ Vassilios Vougioukas, MD, ${ }^{2}$ and Marcos Tatagiba, MD1 \\ 1Department of Neurosurgery, Eberhardt Karls University, Tuebingen, Germany; and ²Department of Neurosurgery, Athens Medical Center, Athens, Greece
}

\begin{abstract}
BACKGROUND Herpes is the most common cause of viral encephalitis in the young population. Herpes meningitis following brain surgery is very rare, however. Only a few cases are reported in the literature, and only one concerned an infection after vestibular schwannoma surgery.

OBSERVATIONS The authors report a case of a 44-year-old patient who developed severe herpes meningitis a few days after removal of a large cystic vestibular schwannoma.
\end{abstract}

LESSONS Herpes simplex virus meningitis following a posterior fossa surgery must be considered when patients develop atypical symptoms a few days after surgery.

https://thejns.org/doi/abs/10.3171/CASE20146

KEYWORDS herpes; meningitis; vestibular schwannoma

The occurrence of herpes infection of the central nervous system (CNS) in the young population is rare. If the infection is not diagnosed early and treated, the mortality rate is approximately $70 \% .^{1,2}$ Many factors are relevant for the development of such an infection among patients, such as stress, immunosuppression, or trauma. ${ }^{3}$ Immunocompetent patients rarely develop a herpes infection after brain surgery. We report a case of a 44-year-old otherwise healthy man who underwent vestibular schwannoma surgery in our department. The patient developed fever 3 days after surgery but showed no other symptoms until 7 days after surgery. On the ninth postsurgical day, the patient developed a generalized epileptic seizure with deterioration of his neurological condition. In the cerebrospinal fluid (CSF) examination, viral (herpes) meningitis was detected. After antiviral treatment with acyclovir, the patient recovered fully. No previous herpes manifestation was reported by the patient.

\section{Illustrative Case}

A 44-year-old man presented to us with a reduction of hearing in the left ear of 12 years' duration. Three years earlier, he had developed imbalance, and his hearing had deteriorated. Follow-up magnetic resonance imaging (MRI) of the head revealed a tumor in the cerebellopontine angle on the left side. One year later, partial resection of the tumor was performed in another hospital. After the surgery, the patient completely lost his hearing on the left side. Histologically, the tumor was a vestibular schwannoma. Follow-up MRI of the head showed progression of the remnant tumor with cystic components (Fig. 1). The patient contacted our department for removal of the large cystic tumor.

Following a retrosigmoidal craniotomy with the patient in semisitting position, a near-total resection with preservation of the facial nerve was performed (Fig. 2). Postoperatively, apart from transient facial palsy (House and Brackmann grade II), the patient did not show any further neurological deficits. On the third postoperative day, the patient developed a fever $\left(38^{\circ} \mathrm{C}\right)$. Urine and CSF examinations were performed, but the results were inconspicuous. The findings of a chest radiograph, a coronavirus disease 2019 smear, and blood cultures were inconspicuous as well. The wound was dry at all times and healed without any complications. There were no signs of herpes manifestation on the patient's face.

One day later, the patient again developed a fever up to $39^{\circ} \mathrm{C}$. He was sleepy and could not give adequate answers to questions. The patient showed significantly reduced vigilance and general condition. He could open his eyes when asked; however, he did not show an adequate response to prompts. His body temperature was $39.4^{\circ} \mathrm{C}$, and he did not show any signs of meningism. A lumbar puncture showed slightly increased leukocytes $(140 / \mu \mathrm{L})$, lactate $(3.4 \mathrm{mmol} / \mathrm{L})$, and

ABBREVIATIONS CNS = central nervous system; CSF = cerebrospinal fluid; HSV = herpes simplex virus; $\mathrm{MRI}=$ magnetic resonance imaging; $\mathrm{PCR}=$ polymerase chain reaction.

INCLUDE WHEN CITING Published February 8, 2021; DOI: 10.3171/CASE20146.

SUBMITTED December 8, 2020. ACCEPTED December 13, 2020.

(C) 2021 The authors, CC BY-NC-ND 4.0 (http://creativecommons.org/licenses/by-nc-nd/4.0/), 

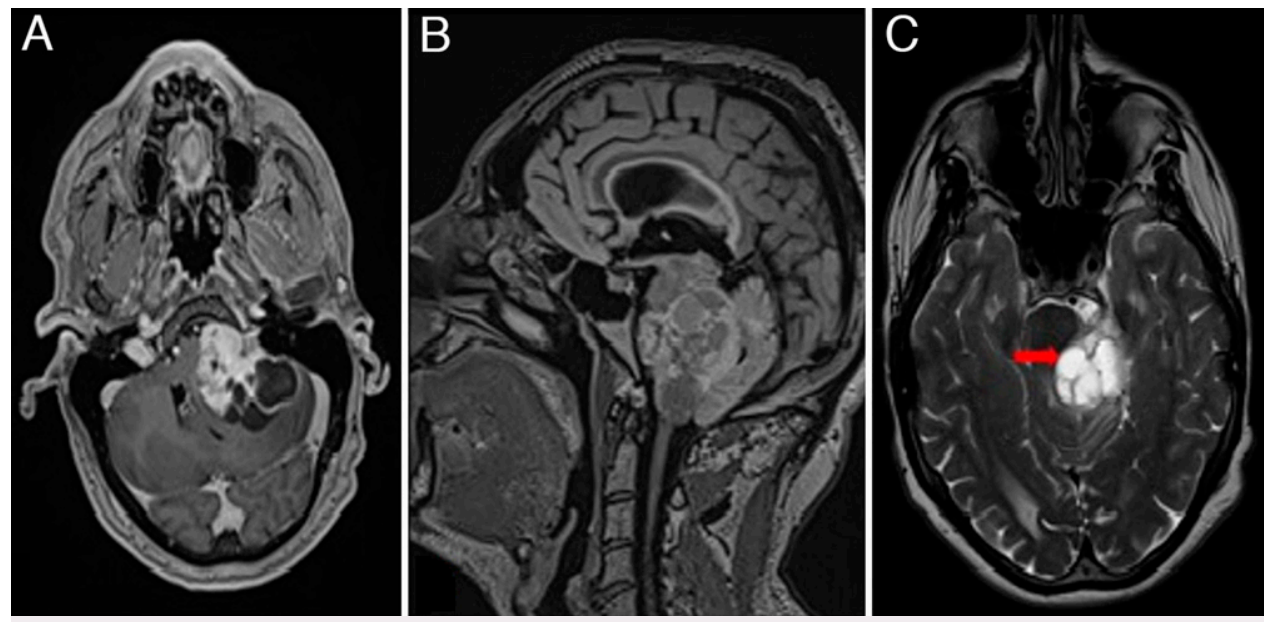

FIG. 1. MRI scans before the second surgery showing a large cystic vestibular schwannoma. A: T1-weighted image in axial plane with gadolinium contrast enhancement. B: Sagittal plane without contrast enhancement. C: Axial T2-weighted image. Red arrowindicates the trigeminal nerve, obviously compressed and displaced by the tumor.

protein (169 mg/dL) and normal glucose $(50 \mathrm{mg} / \mathrm{dL})$. His clinical status deteriorated further, and on the ninth day after surgery, he first experienced consecutive focal seizures followed by a generalized tonicclonic seizure. CSF and blood examinations were repeated to look for a viral infection. Simultaneously, we started empirical antibiotic and antiviral therapy. The patient's MRI examination showed only mild biparietal swelling but was otherwise unremarkable (Fig. 3).

Virological examination of the patient's CSF showed a positive polymerase chain reaction (PCR) result for herpes simplex virus (HSV)-1 DNA, whereas the findings of his bacteriological examination remained negative. The patient presented, for the first time in his life, according to his mother, with an oral cutaneous manifestation of herpes on his upper left lip. The patient's general condition improved over the next few days, and he could be transferred to the neurosurgical ward for further care. He was alert and able to speak and eat on his own. His gait disturbance and memory improved as well, so that he could walk with
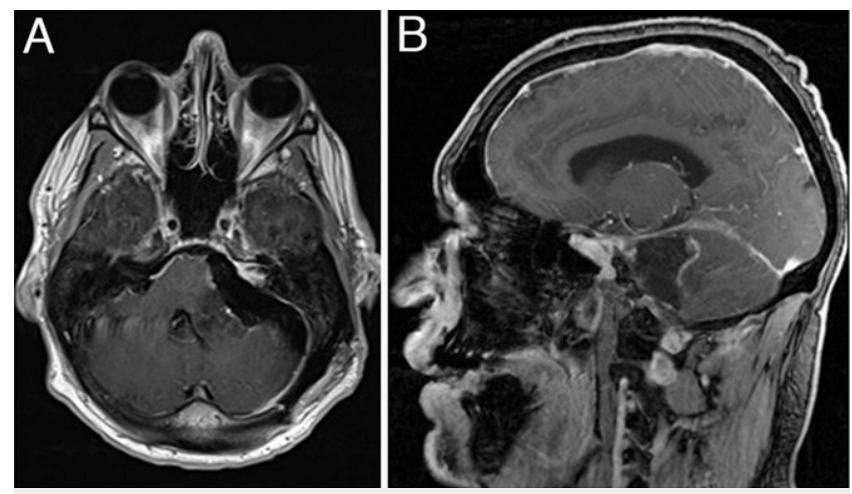

FIG. 2. MRI scans after surgery showing a proper finding after tumor removal. A: T1-weighted image in axial plane with gadolinium contrast enhancement. B: T1-weighted image in sagittal plane with gadolinium contrast enhancement. some support. On the 42nd day after surgery, the patient could be discharged in good neurological and general condition.

\section{Discussion}

This is one of the very few cases yet reported in which a patient with vestibular schwannoma developed herpes meningitis after surgery.

\section{Observations}

Despite the fact that $\mathrm{HSV}$ is carried by almost $80 \%$ of the population in a latent condition, ${ }^{4}$ not everybody shows a herpes manifestation during life. A herpes infection following a neurosurgical procedure is very rare. Few cases are reported in the literature; $1,3,5-115$ of them concerned patients with vestibular schwannomas. ${ }^{6,12-15}$ Only one case of herpes meningitis without encephalitis ${ }^{12}$ has been reported so far. If not immediately treated, herpes meningitis is usually lethal. $3,11,14,16$ In contrast to bacterial meningitis, viral infections of the CNS are easier to oversee. The symptoms are normally nonspecific (e.g., fever, apathy, reduced consciousness or lethargy, nausea), and blood examination offers no specific indicators. In contrast to viral encephalitis, herpes encephalitis does not show severe changes by MRI examination, which makes the diagnosis even more challenging. The fastest way to detect herpes meningitis is to perform PCR of the CSF. ${ }^{2}$ In our patient, notably, the first manifestation of the viral infection was fever on the third day after surgery. More severe symptoms developed on the seventh and ninth days after surgery, when the patient developed seizures, and his condition deteriorated. This short incubation time is not uncommon. In an extended review of viral infections after neurosurgical procedures, an average delay of 6 days between surgery and HSV infection has been reported. ${ }^{3}$

There are 3 dominant theories of how HSV can reactivate after brain surgery: (1) HSV is known to be located in latent status in the sensory ganglia and especially in the trigeminal nerve, so manipulation of the nerve during the surgery may release and spread the virus. (2) Reactivation of a latent CNS infection can occur, as proved after brain tissue examination in healthy individuals. ${ }^{17}$ (3) Spread can occur through the olfactory nerve because of an upper respiratory tract infection. 3,18 

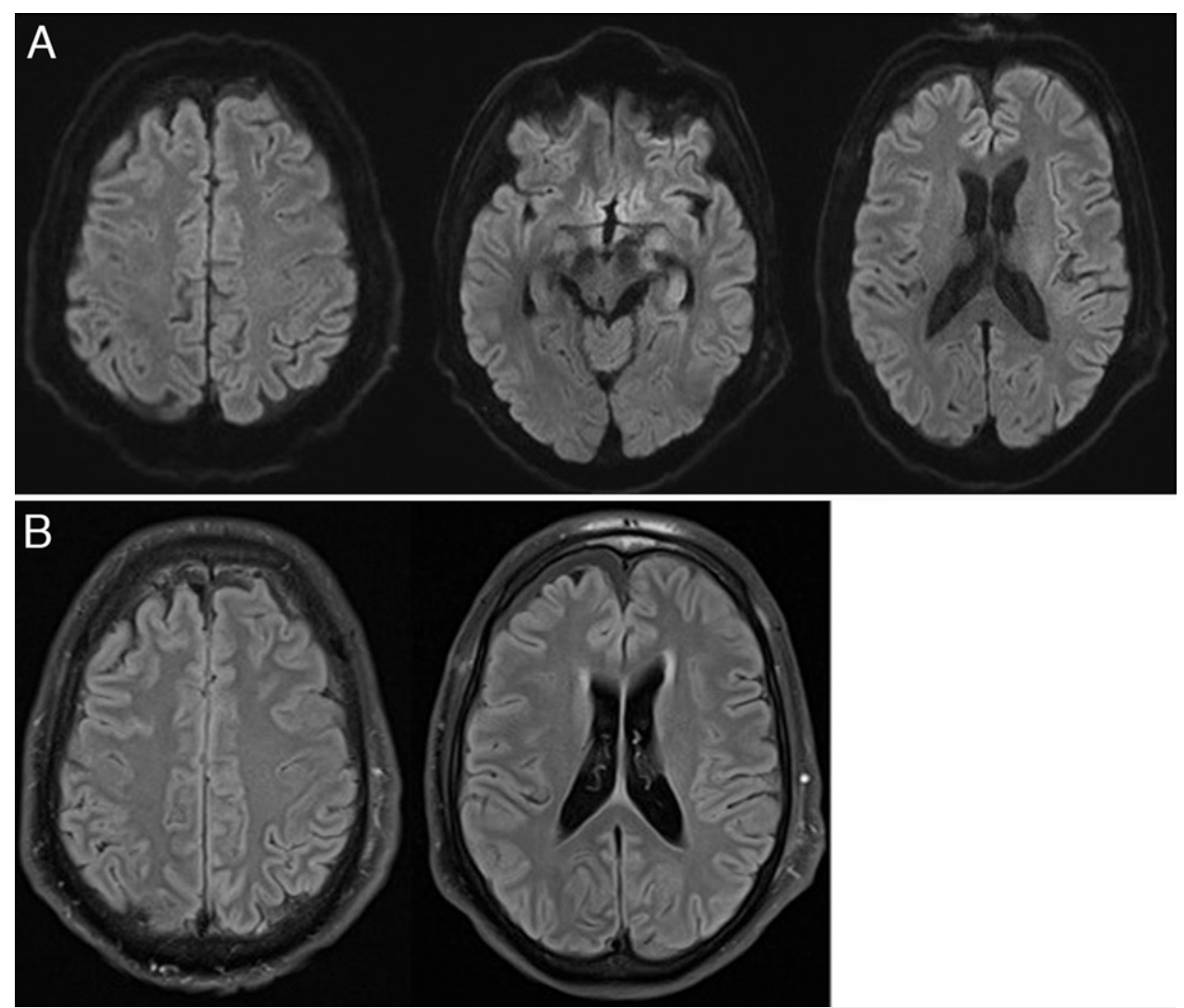

FIG. 3. MRI scans after the generalized epileptic seizure. A: Diffusion sequence showing no pathological findings of encephalitis. B: T2-weighted fluid-attenuated inversion recovery sequence showing slight biparietal swelling, probably caused by the epileptic seizures a few hours earlier.

Moreover, several risk factors are reported to play a supportive role in the reactivation of HSV. These include radiation, immunosuppression, trauma, perioperative steroid treatment, or stress. ${ }^{19}$ In our patient, the trigeminal nerve on the left side was massively displaced through the tumor and was dissected from the tumor during resection. Although the patient showed no additional trigeminal deficit after surgery, he had trigeminal symptoms before surgery. Moreover, he received $20 \mathrm{mg}$ of dexamethasone perioperatively as part of our protocol after posterior fossa surgery for a large tumor. Our hypothesis is that the combination of these 3 factors (trigeminal nerve manipulation, perioperative treatment with dexamethasone, and the stress that the patient experienced perioperatively) played a significant role in the (re)activation of HSV in this case. Despite the fact that the patient had never experienced an HSV manifestation, he probably had latent HSVinfected trigeminal neurons. Through the manipulation of the trigeminal nerve, the virus might have been reactivated. Because of the steroid application and the stress the patient experienced, the virus could finally have led to a meningeal manifestation. The current standard for the treatment of herpes infections of the CNS is acyclovir. ${ }^{2}$ We started acyclovir therapy on the ninth day after surgery, even before we had made the final diagnosis on the basis of positive PCR results in CSF. The patient recovered rapidly and fully with the antiviral medication treatment.

\section{Lessons}

Although rare, HSV meningitis following a posterior fossa surgery must be considered when patients develop atypical symptoms a few days after surgery, such as elevated fever and meningitis symptoms. PCR of the CSF can lead to a definitive diagnosis. An empirical treatment with acyclovir should be considered when a viral infection is suspected and can be of vital importance for the patient if acyclovir treatment is started early.

\section{References}

1. Alonso-Vanegas MA, Quintero-López E, Martínez-Albarrán AA, et al. Recurrent herpes simplex virus encephalitis after neurologic surgery. World Neurosurg. 2016;89:731.e1-731.e5.

2. Tyler KL. Herpes simplex virus infections of the central nervous system: encephalitis and meningitis, including Mollaret's. Herpes. 2004;11(suppl 2):57A-64A.

3. Aldea S, Joly LM, Roujeau T, et al. Postoperative herpes simplex virus encephalitis after neurosurgery: case report and review of the literature. Clin Infect Dis. 2003;36(7):e96-e99.

4. Jalloh I, Guilfoyle MR, Lloyd SKW, et al. Reactivation and centripetal spread of herpes simplex virus complicating acoustic neuroma resection. Surg Neurol. 2009;72(5):502-504.

5. Nabors MW, Francis CK, Kobrine Al. Reactivation of herpesvirus in neurosurgical patients. Neurosurgery. 1986;19(4):599-603. 
6. Elmaci I, Altinoz MA. Recrudescence of herpes virus infections following resection of schwannomas. An antiviral role of merlin? Med Hypotheses. 2017;102:128-129.

7. Uda $T$, Koide $R$, Ito $H$, et al. Relapse of herpes simplex virus encephalitis after surgical treatment for temporal lobe epilepsy: rare complication of epilepsy surgery. J Neurol. 2013;260(1): 318-320.

8. Manz HJ, Phillips TM, McCullough DC. Herpes simplex type 2 encephalitis concurrent with known cerebral metastases. Acta Neuropathol. 1979;47(3):237-240.

9. Sheleg SV, Nedzved MK, Nedzved AM, et al. Contamination of glioblastoma multiforme with type 1 herpes simplex virus. Case illustration. J Neurosurg. 2001;95(4):721.

10. Pazin GJ, Ho M, Jannetta PJ. Reactivation of herpes simplex virus after decompression of the trigeminal nerve root. J Infect Dis. 1978; 138(3):405-409.

11. Arnold A, Parkins MD, Hamilton LE, et al. Recurrent herpes simplex virus encephalitis after epilepsy surgery. Can J Neurol Sci. 2019;46(2):261-263.

12. Mallory GW, Wilson JW, Castner ML, et al. Herpes simplex meningitis after removal of a vestibular schwannoma: case report and review of the literature. Otol Neurotol. 2012;33(8): 1422-1425.

13. Prasad GL, Kumar V, Menon G. Delayed facial palsy after microvascular decompression: report of two cases. J Neurosci Rural Pract. 2017;8(3):461-465.

14. Spuler A, Blaszyk H, Parisi JE, et al. Herpes simplex encephalitis after brain surgery: case report and review of the literature. J Neurol Neurosurg Psychiatry. 1999;67(2):239-242.

15. Filipo R, Attanasio G, De Seta E, et al. Post-operative herpes simplex virus encephalitis after surgical resection of acoustic neuroma: a case report. J Laryngol Otol. 2005;119(7):558-560.
16. Fearnside MR, Grant JM. Acute necrotizing encephalitis complicating bifrontal craniotomy and pituitary curettage. Report of two cases. J Neurosurg. 1972;36(4):499-502.

17. Fauci AS, ed. Harrison's Principles of Internal Medicine: Companion Handbook. 14th ed. McGraw-Hill; 1998.

18. Dinn JJ. Transolfactory spread of virus in herpes simplex encephalitis. Br Med J. 1980;281(6252):1392.

19. Savage S. Post-operative herpes simplex virus encephalitis after surgical resection of acoustic neuroma: a case report. Redorbit. Accessed November 12, 2020. https://www.redorbit.com/news/ health/189301/postoperative_herpes_simplex_virus_ encephalitis_after_surgical_resection_of_acousticl

\section{Disclosures}

The authors report no conflict of interest concerning the materials or methods used in this study or the findings specified in this paper.

\section{Author Contributions}

Conception and design: Trakolis, Tatagiba. Acquisition of data: Trakolis, Tatagiba. Analysis and interpretation of data: Trakolis, Naros, Tatagiba. Drafting the article: Trakolis, Naros. Critically revising the article: all authors. Reviewed submitted version of manuscript: Trakolis. Approved the final version of the manuscript on behalf of all authors: Trakolis. Statistical analysis: Trakolis. Administrative/technical/material support: Trakolis. Study supervision: Trakolis. Responsible for the clinical case and surgery on the patient: Tatagiba.

\section{Correspondence}

Leonidas Trakolis: Eberhardt Karls University, Tuebingen, Germany. leonidas.trakolis@med.uni-tuebingen.de. 